\title{
Resistência de genótipos de tomateiro ao ácaro rajado
}

\author{
Wilson Itamar Maruyama; Luciana Cláudia Toscano; Arlindo L. Boiça Júnior; José Carlos Barbosa. \\ UNESP, Via de Acesso Paulo Donato Castellane, s/n, 14.870-000 Jaboticabal-SP; Email:wilsonmaruyama@yahoo.com.br; \\ aboicajr@fcav.unesp.br
}

\begin{abstract}
RESUMO
Avaliou-se a resistência de genótipos de tomateiro selvagens [Lycopersicon pennellii (LA 716), L. hirsutum var. glabratum (PI 126449, PI 134417), L. hirsutum (PI 127826, PI 127827), L. peruvianum (CGO 6707), L. peruvianum var. dentatum (WYR 2020, LA 111), L. peruvianum var. glandulosum (LA 1113-1, LA 1113-2)] e comerciais [(L. esculentum) Gem Pride, Santa Clara, e híbridos Bruna VFN, Carmem, Fortaleza, Débora Plus VFN] ao ácaro rajado (Tetranychus urticae). O número médio de ovos, fases imaturas (larvas, protoninfas e deutoninfas) e adultos por folíolo foi contado; o índice de preferência para oviposição (IPO) foi calculado. O delineamento experimental foi blocos ao acaso, com 6 repetições. Os genótipos LA 716, PI 126449, PI 134417, PI 127827, PI 127826 e Gem Pride apresentaram não-preferência para oviposição do ácaro rajado, sendo deterrentes quanto à classificação do IPO, enquanto os genótipos LA 111, WYR 2020, LA 1113-2 e LA1113-1 foram os mais preferidos para a oviposição e foram considerados como estimulantes pelo IPO.
\end{abstract}

Palavras-chaves: Tetranychus urticae, Lycopersicon esculentum, L. pennellii, L. hirsutum, L. peruvianum, resistência de plantas.

\begin{abstract}
\section{Resistance of tomato genotypes to spider mite}

The resistance of different tomato genotypes to spider mite (Tetranychus urticae) was evaluated. The wild genotypes evaluated were Lycopersicon pennellii (LA 716), L. hirsutum f. glabratum (PI 126449, PI 134417), L. hirsutum (PI 127826, PI 127827), L. peruvianum (CGO 6707), L. peruvianum $\mathrm{f}$. dentatum (WYR 2020, LA 111), L. peruvianum f. glandulosum (LA 1113-1, LA 1113-2); and the commercial genotypes (L. esculentum) were Gem Pride, Santa Clara, and the F1 hybrids Bruna VFN, Carmem, Fortaleza and Débora Plus VFN. The number of eggs was counted, young phases (larvae, protonimphs, deutonimphs) and adults per leafleft. After the counting, the index of oviposition preference (IOP) also was calculated. The experiment was realized in randomized block design, with six replications. The LA 716, PI 126449, PI 134417, PI 127827, PI 127826 and Gem Pride genotypes showed non-preference for spider mite oviposition, being deterrents through IOP classification, while LA 111, WYR 2020, LA 1113-2 and LA1113-1 genotypes were the more preferred for oviposition and stimulants for oviposition by the IOP.
\end{abstract}

Keywords: Tetranychus urticae, Lycopersicon esculentum, L. pennellii, L. hirsutum, L. peruvianum, resistance of plant.

\section{(Recebido para publicação em 23 de outubro de 2001 e aceito em 25 de março de 2002 ).}

A cultura do tomateiro é afetada por várias pragas, entre as quais, destaca-se o ácaro rajado (Koch, 1836). Este ataca as folhas situadas na parte mediana da planta, causando amarelecimento e secamento (Flechtmann,1972), com diminuição do número e tamanho dos frutos, indução da maturação precoce e baixo teor de sólidos solúveis (Minami, 1980). O ácaro rajado possui grande gama de hospedeiros (Minami, 1980) e de acordo com Atherton \& Rudich (1986) aparece principalmente em condições de cultivo protegido, preferindo ambientes de baixa umidade.

Os ácaros possuem enorme capacidade de aumento populacional, chegando a 20-25 gerações por ano. Desta forma, o controle do ácaro precisa ser eficiente, mantendo a população abaixo do nível de dano econômico. Atualmente, o controle químico é o mais utilizado, porém, o mais problemático, porque os ácaros possuem elevada aptidão para desenvolver resistência contra vários grupos de acaricidas. Omoto et al. (2000) em bioensaios de laboratório verificaram uma razão de resistência de aproximadamente 57 vezes ao princípio ativo dicofol para a linhagem resistente do ácaro Brevipalpus phoenicis quando comparada a linhagem suscetível. Para T. urticae (Mansour \& Plaut, 1979) e Tetranychus cinnabarinus (FergussonKolmes et al., 1991) foi detectada resistência aos princípios ativos dicofol e bromopropilato. Esta resistência, provavelmente ocorreu em função da utilização de dosagens não recomendadas de acaricidas e elevada freqüência de pulverização (Gravena, 1994). A fím de diminuir o problema de resistência de praga aos acaricidas, o uso de cultivares resistentes para o controle do ácaro pode ser de grande contribuição, por tratar-se de um método eficaz, já que dei$\mathrm{xa}$ as populações abaixo do nível econômico de dano. Este tipo de controle pode ser obtido através do melhoramen- to genético de plantas, sendo a planta melhorada menos danificada em relação à suscetível em igualdade de condições. O método possui efeito permanente sobre a população da praga, não afeta diretamente seus inimigos naturais e dispensa o agricultor de qualquer conhecimento sobre a praga para efetuar o controle (Lara, 1991).

A resistência de plantas deve ser considerada relativa. Assim um material genético pode comportar-se como resistente ou suscetível dependendo do ensaio e das condições ambientais. A preferência ou não de uma planta é classificada como um dos tipos de resistência, podendo ser observada quando a planta é mais ou menos utilizada pelo ácaro para alimentação, oviposição ou mesmo abrigo (Lara, 1991). Os estímulos emitidos pela planta que atuam no comportamento do ácaro, podem ser, estimulantes e deterrentes, entre outros. Quando a planta libera estímulo positivo (estimulante) induz o ácaro à 
oviposição e/ou alimentação, enquanto a emissão de estímulo negativo (deterrente) impede a continuidade da oviposição e/ou alimentação (Lara, 1991).

As plantas apresentam diversos mecanismos de proteção a insetos e ácaros, como os tricomas, responsáveis pela proteção das folhas e caules, importantes no gênero Lycopersicon (Chatzivasileiadis \& Sabelis, 1997). A resistência de plantas ao ácaro rajado tem sido relatada em função de várias características da superfície dos folíolos, incluindo densidade e componentes químicos encontrados em tricomas glandulares (Gentile et al., 1969; Aina et al., 1972; Snyder \& Carter, 1984; Rasmy, 1985), como é o caso das densidades de tricomas glandulares do tipo IV (Snyder \& Carter, 1984) e tricomas não glandulares do tipo V (Carter \& Snyder, 1985).

Os exsudatos dos tricomas do tipo VI da espécie L. hirsutum var. typicum são tóxicos e repelentes ao ácaro rajado (Aina et al., 1972) e a remoção das glândulas dos tricomas reduziram, mas não eliminaram a resistência aos ácaros (Snyder \& Carter, 1984; Rasmy, 1985). A densidade de tricomas glandulares do tipo IV influenciaram no comportamento e resistência dos ácaros sobre os folíolos de Lycopersicon spp.

A classificação de espécies vegetais em graus de resistência ou suscetibilidade pode ser feita de várias formas. Atualmente alguns autores vêm utilizando o Índice de Preferência para Oviposição (IPO) para facilitar esta distinção. O uso do IPO auxilia na seleção de genótipos resistentes, separando-os em níveis de deterrência, neutralidade e estimulação em relação à preferência da praga (Fenemore, 1980). O presente trabalho teve como objetivo avaliar a incidência natural de $T$. urticae em diferentes genótipos de tomateiro, para verificar sua resistência ao ácaro.

\section{MATERIAL E MÉTODOS}

Os testes foram realizados em casade-vegetação da UNESP, Jaboticabal (SP). A semeadura foi realizada em 13/ 10/1998, em bandejas de poliestireno expandido contendo substrato agrícola à base de cascas de pinus trituradas $\mathrm{e}$ compostadas $($ marca $=$ Plantmax $)$. Plântulas de 28 dias de idade foram transplantas para vasos de 3 litros de capacidade, contendo três partes de solo, uma parte de areia e uma parte de composto orgânico. A adubação dos vasos foi realizada de acordo com a análise de solo, com 1,5 g de superfosfato simples, $0,3 \mathrm{~g}$ de cloreto de potássio e $0,3 \mathrm{~g}$ de nitrato de amônio por $\mathrm{kg}$ de solo antes do plantio. Aos 15 e 25 dias após o transplante realizou-se adubação de cobertura com 0,3 g de nitrato de amônio/ $\mathrm{kg}$ de solo.

Os tratamentos consistiram de 10 genótipos selvagens [Lycopersicon pennellii (LA 716), L. hirsutum var. glabratum (PI 126449, PI 134417), L. hirsutum (PI 127826, PI 127827), L. peruvianum (CGO 6707), L. peruvianum var. dentatum (WYR 2020, LA 111), L. peruvianum var. glandulosum (LA 1113-1, LA 1113-2)] e seis genótipos comerciais ( $L$. esculentum) (Gem Pride, Santa Clara e os híbridos Bruna Plus VFN, Carmem, Fortaleza e Débora Plus VFN.

A incidência natural do ácaro rajado foi avaliada em gaiolas revestidas com tela antiafídeo com $2 \times 3 \mathrm{~m}$ de base e 2 $\mathrm{m}$ de altura, contendo 16 vasos com uma planta de cada genótipo por recipiente. As avaliações foram realizadas durante cinco semanas, em intervalos semanais, com início aos 49 dias de idade das plantas, coletando-se três folíolos por planta, dos terços superior, médio e inferior. Os folíolos foram levados ao laboratório e com o auxílio de um microscópio estereoscópico, contou-se o número de ovos, fases imaturas (larvas, protoninfas e deutoninfas) e adultos do ácaro na face abaxial de cada folíolo. Posteriormente, calculou-se o IPO através da expressão proposta por Fenemore (1980), [(A$\mathrm{B}) /(\mathrm{A}+\mathrm{B})]$ x 100 , onde $\mathrm{A}=$ número de ovos contados no genótipo avaliado e $\mathrm{B}$ = número de ovos contados no genótipo padrão. O índice varia de +100 (muito estimulante), zero (neutro), até -100 (total deterrência ou inibição de oviposição). Os valores de número de ovos/folíolo foram submetido à análise de variância pelo teste $\mathrm{F}$, e comparados pelo teste de Tukey a 5\% de probabilidade. A classificação dos genótipos (deterrente/estimulante) foi determina- da comparando-se o índice do genótipo padrão (Santa Clara), levando-se em conta o erro padrão da média, com o dos tratamentos. O delineamento experimental foi blocos ao acaso, com 16 genótipos (tratamentos), seis blocos (gaiolas).

\section{RESULTADOS E DISCUSSÃO}

Quanto ao número médio de ovos do ácaro rajado observou-se diferenças significativas pelo teste de Tukey entre os genótipos, sendo os menos ovipositados, PI 126449 (0,0 ovos/folíolo), PI 134417 (0,0 ovos/folíolo), LA 716 (0,0 ovos/ folíolo), PI 127827 (0,1 ovos/folíolo), Gem Pride (0,5 ovos/folíolo), PI 127826 ( 0,8 ovos/folíolo) e híbrido Fortaleza (1,3 ovos/folíolo), em relação ao LA 1113-1 com maior oviposição (49,7 ovos/folíolo) (Tabela 1). Os demais genótipos comportaram-se como intermediários variando de 1,9 a 40,8 ovos/ folíolo. A maior ou menor preferência para postura em determinados genótipos, segundo Chiavegato \& Mischan (1981), indica diferentes graus de resistência dos materiais utilizados, com relação ao ataque da praga.

Ao analisar o número de ovos/ folíolo, pelo teste de Tukey, não houve diferenciação entre os genótipos selvagens e comerciais do padrão (Santa Clara). Este fato foi também observado por Baldin et al. (2000), quando verificaram a preferência para oviposição de Bemisia tabaci biótipo "B" por genótipos de Curcubita moschata e Curcubita maxima (genótipo padrão).

Com a utilização do IPO foi possível a diferenciação entre genótipos pouco ovipositados e aqueles com alta postura obtendo-se o grau de preferência (Tabela 1). Os materiais LA 716, PI 126449, PI 134417, PI 127827, Gem Pride, PI 127826, híbrido Fortaleza, Carmem e Débora Plus VFN apresentaram alto índice de deterrência com relação ao padrão (Santa Clara). Os genótipos LA 1113-1, LA 1113-2, WYR 2020 e LA 111 mostraram-se como estimulantes à oviposição, enquanto, CGO 6707 e híbrido Bruna Plus VFN igualaram-se ao padrão de neutralidade. Os híbridos Fortaleza, Carmem e Débora Plus VFN apresentaram um desempe- 
Tabela 1. Número médio de ovos, índice de preferência para oviposição (IPO) e classificação dos genótipos de tomateiro quanto a preferência para oviposição de Tetranychus urticae. Jaboticabal, UNESP, 1999.

\begin{tabular}{lccc}
\hline \multicolumn{1}{c}{ Genótipos } & $\mathbf{N}^{\circ}$ de ovos/folíolo & IPO & Classificação pelo IPO \\
\hline LA 716 & $0,00 \mathrm{c}$ & $-100,00$ & Deterrente \\
PI 126449 & $0,00 \mathrm{c}$ & $-100,00$ & Deterrente \\
PI 134417 & $0,00 \mathrm{c}$ & $-100,00$ & Deterrente \\
PI 127827 & $0,06 \mathrm{c}$ & $-99,41$ & Deterrente \\
Gem Pride & $0,50 \mathrm{bc}$ & $-95,17$ & Deterrente \\
PI 127826 & $0,78 \mathrm{bc}$ & $-92,57$ & Deterrente \\
H. Fortaleza & $1,28 \mathrm{bc}$ & $-88,09$ & Deterrente \\
H. Carmem & $1,94 \mathrm{abc}$ & $-82,49$ & Deterrente \\
H. Débora Plus & $3,27 \mathrm{abc}$ & $-72,16$ & Deterrente \\
H. Bruna Plus VFN & $20,10 \mathrm{abc}$ & $-0,30$ & Neutro \\
Santa Clara & $20,22 \mathrm{abc}$ & 0,00 & Padrão \\
CGO 6707 & $24,21 \mathrm{abc}$ & $+8,98$ & Neutro \\
LA 111 & $36,38 \mathrm{abc}$ & $+28,55$ & Estimulante \\
WYR 2020 & $40,61 \mathrm{abc}$ & $+33,52$ & Estimulante \\
LA 1113-2 & $40,83 \mathrm{ab}$ & $+33,76$ & Estimulante \\
LA 1113-1 & $49,71 \mathrm{a}$ & $+42,17$ & Estimulante \\
\hline F (tratamento) & $4,41^{* *}$ & & \\
C.V. (\%) & 36,42 & & \\
\hline
\end{tabular}

${ }^{1 / M e ́ d i a s ~ s e g u i d a s ~ d e ~ m e s m a ~ l e t r a ~ n a ~ c o l u n a ~ n a ̃ o ~ d i f e r e m ~ s i g n i f i c a t i v a m e n t e ~ e n t r e ~ s i ~ p e l o ~ t e s t e ~ d e ~ T u k e y ~ a ~} 5 \%$ de probabilidade. Médias originais; para análise estatística os dados foram transformados em $\log (\mathrm{x}+5)$.

${ }^{2 /} \mathrm{IPO}$ - Índice de Preferência para Oviposição [(A-B)/(A+B)]x100 - A = número de ovos contados no genótipo avaliado e B = número de ovos contados no genótipo padrão; EP - Erro Padrão da média = 26,59.

nho satisfatório frente a cultivar Santa Clara (padrão), indicando que alguns componentes antixenóticos e/ou antibióticos de resistência podem ter sido incorporados quando se realizou o seu melhoramento genético. Por exemplo, a introdução de genes responsáveis pela presença de tricomas glandulares do tipo VI ou tipo IV, que possuem exsudatos químicos e aderentes, respectivamente.

Para o número médio de formas imaturas os genótipos LA 716, PI 126449, PI 134417 não apresentaram nenhum indivíduo, e os genótipos híbrido Carmem, Gem Pride, PI 127826, PI 127827 (com 0,7, 0,4, 0,1 e 0,1 fases imaturas/folíolo, respectivamente) diferiram dos materiais híbrido Bruna Plus VFN, CGO 6707 e LA 1113-1 (21,6, 14,2 e 14,9 fases imaturas/folíolo, respectivamente). Com relação aos outros genótipos não foram observadas diferenças significativas, ou seja, permaneceram com resistência intermediária.

Quanto ao número médio de adultos por folíolo não se observou diferen- ças significativas entre os genótipos (Tabela 2). Acredita-se que materiais resistentes não são atrativos ou são deterrentes para oviposição/alimentação dos ácaros, podendo não ser encontrados, ou mesmo encontrando-se alguns, estes realizam poucas posturas, como ocorreu no presente trabalho, pelo baixo número de ovos e fases imaturas verificados (Tabelas 1 e 2). De acordo com Williams et al. (1980) essa não-preferência para oviposição está relacionada com a presença de tricomas que possuem o "inseticida natural" (2-tridecanona) produzido por tricomas glandulares do tipo VI. Ainda com relação ao PI 134417, Chatzivasileiadis \& Sabelis (1997) verificaram em seus tricomas, elevada presença de metil cetonas, substâncias altamente tóxicas a esses ácaros, sendo que, em L. esculentum foram encontrados menor número de tricomas com esse componente químico, o que indica ser necessário um maior contato do ácaro com mais tricomas para provocar a sua morte.

A resistência pode ocorrer devido ao tipo de tricoma ou densidade, e presença de exsudato químico, como foi relatado por Snyder \& Carter (1984), que encontraram na superfície inferior da folha em plantas de L. hirsutum a postura de 0,2 ovos/fêmea, enquanto, em plantas de L. esculentum foi de 9,4 ovos/ fêmea, o que salienta a importância de genótipos selvagens como fonte de resistência. Porém, o fato de um genótipo ser selvagem não caracteriza que seja resistente, ou que possua algum tipo de resistência a determinada praga, o que foi evidenciado no presente experimento pela preferência do ácaro rajado para oviposição nos genótipos selvagens LA 1113-2 e LA 1113-1. Acredita-se que a suscetibilidade à oviposição desses genótipos possa estar relacionada com a ausência, ou a menor quantidade de tricomas glandulares, visto a importância desses no fator resistência do genótipo PI 134417 observada por Williams et al. (1980). Ainda com rela- 
Tabela 2. Número médio de fases imaturas e adultos de Tetranychus urticae por folíolo de diferentes genótipos de tomateiro. Jaboticabal, UNESP, 1999.

\begin{tabular}{lcc}
\hline Genótipos & $\begin{array}{c}\text { Número de fases } \\
\text { imaturas/folíolo }\end{array}$ & Número de adultos/folíolo" $^{1 /}$ \\
\hline LA 716 & $0,00 \mathrm{~b}$ & $0,00 \mathrm{a}$ \\
PI 126449 & $0,00 \mathrm{~b}$ & $0,00 \mathrm{a}$ \\
PI 134417 & $0,00 \mathrm{~b}$ & $0,05 \mathrm{a}$ \\
PI 127827 & $0,06 \mathrm{~b}$ & $0,11 \mathrm{a}$ \\
Gem Pride & $0,38 \mathrm{~b}$ & $0,39 \mathrm{a}$ \\
PI 127826 & $0,11 \mathrm{~b}$ & $0,44 \mathrm{a}$ \\
Híbrido Fortaleza & $1,27 \mathrm{ab}$ & $0,27 \mathrm{a}$ \\
H. Carmem & $0,66 \mathrm{~b}$ & $0,60 \mathrm{a}$ \\
H. Débora Plus & $1,72 \mathrm{ab}$ & $0,72 \mathrm{a}$ \\
H. Bruna Plus VFN & $21,60 \mathrm{a}$ & $4,27 \mathrm{a}$ \\
Santa Clara & $7,04 \mathrm{ab}$ & $3,94 \mathrm{a}$ \\
CGO 6707 & $14,21 \mathrm{a}$ & $3,50 \mathrm{a}$ \\
LA 111 & $8,16 \mathrm{ab}$ & $3,52 \mathrm{a}$ \\
WYR 2020 & $7,77 \mathrm{ab}$ & $2,05 \mathrm{a}$ \\
LA 1113-2 & $2,82 \mathrm{ab}$ & $3,55 \mathrm{a}$ \\
LA 1113-1 & $14,94 \mathrm{a}$ & $2,27 \mathrm{a}$ \\
\hline F (tratamento) & $4,52 * *$ & $2,27 \mathrm{~ns}$ \\
C.V. (\%) & 24,04 & 17,06 \\
\hline
\end{tabular}

${ }^{1 / M e ́ d i a s ~ s e g u i d a s ~ d e ~ m e s m a ~ l e t r a ~ n a ~ c o l u n a ~ n a ̃ o ~ d i f e r e m ~ s i g n i f i c a t i v a m e n t e ~ e n t r e ~ s i ~ p e l o ~ t e s t e ~ d e ~ T u k e y ~ a ~} 5 \%$ de probabilidade. Médias originais; para análise estatística os dados foram transformados em $\log (\mathrm{x}+5)$.

ção ao LA 1113-1, a ocorrência de elevado número de fases imaturas, possivelmente, caracteriza a ausência ou a baixa concentração de componentes antibióticos, o que pode ter facilitado o desenvolvimento dessas fases. Outro fato, é que uma espécie de Lycopersicon possui vários acessos ou linhagens, com diferentes características morfológicas e fisiológicas, que possivelmente, pode contribuir na variação do fator resistência, atuando sobre um inseto ou ácaro. Por exemplo, Thomazini et al. (2001) verificaram resistência do tipo antibiose do acesso LA 444-1 de L. peruvianum sobre os aspectos biológicos de Tuta absoluta (Meyrick) em relação ao genótipo Santa Clara.

Considerando que o uso de variedades resistentes é um importante método de controle dentro do manejo integrado de pragas, o conhecimento do comportamento de diversos genótipos de tomateiro ao ataque do ácaro rajado pode ser de grande valia para o melhoramento de plantas visando produzir materiais resistentes.

\section{AGRADECIMENTOS}

À Embrapa Hortaliças por fornecer as sementes dos genótipos selvagens de tomateiro e as empresas Agroflora, Hortec e SVS-sementes pelas sementes dos genótipos comerciais.

\section{LITERATURA CITADA}

AINA, O.J., RODRIGUEZ, J.G. KNAVEL, D.E. Characterizing resistance to Tetranychus urticae Koch. in tomato. Journal of Economic Entomology. v. 65, p. 641-43, 1972.

ATHERTON, J.G., RUDICH, J. The tomato crop - a scientific bases for improvement. 1986. $661 \mathrm{p}$. London: Chapamn and Hall CHAPTER 10. Pests. BERLINGER. M.I. p. 391-441.

BALDIN, E.L.L., TOSCANO, L.C., LIMA, A.C.S., LARA, F.M., BOIÇA JÚNIOR., A.L. Preferência para Oviposição de Bemisia tabaci biótipo "B" por genótipos de Cucurbita moschata e Cucurbita maxima. Boletin Sanidad Vegetal Plagas, v. 26, p. 409-413, 2000.

CARTER, C.D., SNYDER, J.C. Mite responses in relation to trichomes of Lycorpesicon esculentum x L. hirsutum $\mathrm{F}_{2}$ hybrids. Euphytica. v. 34, p. 177-85, 1985.
CHATZIVASILEIADIS, E.A., SABELIS, M.W. Toxicity of methyl ketones from tomato trichomes to Tetranychus urticae koch. Experimentalis et. Applicata Acarology, v. 21, p. 473-84, 1997.

CHIAVEGATO, L.G., MISCHAN, M.M. Resistência de variedade de tomateiro Lycopersicon esculentum Mill. ao ácaro Tetranychus (T.) urticae (Koch, 1836) Boudreaux \& Dosse, 1963 (Acari, Tetranychidae) em condições de laboratório. $\mathrm{Ci}$ entífica, São Paulo, v. 9, n. 2, p. 267-71, 1981.

FENEMORE, P.G. Oviposition of potato tuber moth, Phthorimaea operculella Zell. (Lepidoptera: Gelechiidae); identification of host plant factors influencing oviposition response. New Zealand Journal of Zoology, v. 7, p. 435-9, 1980.

FERGUSSON-KOLMES, L.A., SCOTT, J.G., DENNEHY, T.J. Dicofol resistance in Tetranychus urticae (Acari: Tetranychidae): cross-resistance and pharmacokinetics. Journal of Economic Entomology, n. 84, p. 41-48, 1991.

FLECHTMANN, C.H.W. Ácaros de importância agrícola. São Paulo, Ed. Nobel, 1972.

GENTILE, A.G., WEBB, R.E., STONER, A.K. Lycopersicon and Solanum spp. resistant to the carmine and two-spotted spider mite. Journal of Economic Entomology, v. 62, p. 834-6, 1969.

GRAVENA, S. Rotação de acaricidas no MIPCitros: menos desequilíbrio e resistência. Laranja, Cordeirópolis, n. 15, p. 375-395, 1994.

LARA, F.M. Principios de resistência de plantas a insetos. São Paulo, Ícone, 2 ed., 1991, p. 45-97. 
MANSOUR, F.A., PLAUT, H.N. The effectiveness of various acaricides against resistant and suscetible carmine spider mites. Phytopathology, n. 7, p. 185-193, 1979.

MINAMI, K. O tomateiro. Campinas, Fundação Cargill, 2. ed., 1980, 310 p.

OMOTO, C., ALVES, E.B., RIBEIRO, P.C Detecção e monitoramento da resistência de Brevipalpus phoenicis (Geijskes) (Acari Tenuipalpidae) ao dicofol. Anais da Sociedade Entomológica do Brasil, Londrina, v. 29, n. 4, p. 757-764, 2000.
RASMY, A.H. The biology of the two-spotted mite Tetranychus urticae as affected by resistant solanaceous plants. Agriculture Ecossistems Enviromental, v. 13, p. 325-28. 1985.

SNYDER, J.C., CARTER, C.D. Leaf trichomes and resistance of Lycopersicon hirsutum and $L$. esculetum to spider mites. Journal of America Society Horticulture Science, v. 109, n. 6, p. 83743, 1984.
THOMAZINI, A.P.B.W., VENDRAMIM, J.D. BRUNHEROTTO, R., LOPES, M.T.R. Efeito de genótipos de tomateiro sobre a biologia e oviposição de Tuta absoluta (Meyrick) (Lep.: Gelechiidae). Neotropical Entomology, Londrina, v. 30, n. 2, p. 283-88, 2001.

WILLIAMS, W.G., KENNEDY, G.G., YAMAMOO, R.T., THACKER, J.D., BORDNER, J. 2-tridecanone: A naturally ocorring inseticide from the wild tomato Lycopersicon hirsutum $\mathrm{f}$. glabratum. Science, v. 207, p. 888-89, 1980. 